\title{
窒化処理 $\mathrm{Ti}$ の諸性質についで
}

\section{中野弘一** 山本俊二** 小林 弘** 高 村 昭**}

Koichi Nakano, Shunji Yamamoto, Hiroshi Kobayashi and Akira Takamura: The Properties of Nitrided Titanium.

Laboratory tests were carried out on the wear resistance, corrosion resistance and mechanical properties of titanium nitrided in nitrogen stream at $850^{\circ} \mathrm{C}$ for $16 \sim 80 \mathrm{hr}$. The wear resistance of titanium was remarkably improved by nitriding. According to the results of sliding experiments, nitrided titanium showed satisfactory surface properties in combinations with the following materials: Cast iron, hard chromium plating and nitrided titanium itself respectively in unlubricated conditions; bronze, cast iron, carbon steel, low alloy steel, Carbaite, bakelite, hard chromium plating and nitrided titanium itself respectively in lubricated conditions. On the whole, the corrosion resistance of titanium was not affected adversely by nitriding and, further, it was interesting to note that the nitriding even improved the resistance in reducing environments. The effect of nitriding on the mechanical properties of titanium was negligible.

(Received March 2, 1960)

\section{I. 緒}

$\mathrm{Ti}$ の耐摩耗性改善を目的とする窒化法の実用性を論ず
る場合には，窒化方法のみならず窒化処理 Ti の耐摩耗性 ならびに Ti の諸性質に及ぼす窒化の影響を検討しなけれ

* 1958年 4 月本会東京大会に発表；Ti の表面 硬化に 関する研究 (第 2 報) 
ばならない，従来窒化処理 $\mathrm{Ti}$ の諸性質について 報告され ている例は稀であり，僅かに吉田一磯野(1)が耐摩耗性につ いて，またBungardt-Rüdinger (2)が機械的性質について 簡単な報告を行つているのみである. 前報(3)では窒素ガス によろ窒化法について述べたが，今回は窒化処理 $\mathrm{Ti}$ の耐 摩耗性，機械的性質ならびに耐食性について述べる。

\section{1. 試 料}

\section{II. 試料ならびに実験方添}

消耗電極二重熔解法による $500 \mathrm{~kg}$ インゴットより分塊 㸝よび鍛造を経て製作した直径 $35 \mathrm{~mm}$ の丸棒を $700^{\circ} \times 1$ $\mathrm{hr}$ 暁鈍し, これより所要の摩耗試験片, 抗張試験片なら びに衝撃試験片を製作した. その化学成分を Table 1 に示 す. 㕍食試験片は前報(3)で用いた厚さ $2 \mathrm{~mm}$ の板より製作 した.

Table 1 Chemical composition of specimen.

\begin{tabular}{|c|c|c|c|c|c|c|}
\hline & $\mathrm{Fe}$ & $\mathrm{Si}$ & $\mathrm{O}_{2}$ & $\mathrm{~N}_{2}$ & $\mathrm{H}_{2}$ & $\mathrm{Ti}$ \\
\hline$\%$ & $<0.05$ & $<0.05$ & 0.083 & 0.031 & 0.005 & $\mathrm{Ba} 1$ \\
\hline
\end{tabular}

\section{2. 糜耗試験}

アムスラ一摩耗試験機により乾燥ならびに給油状態に拉 いて窒化処理 Ti と種々な材料の組合せについて摺動摩耗
$5 \mathrm{cc} / \mathrm{min}$ の割合で 給油した。試験片の温度上杽は Fig. 1 に示したごとく固定片の摺動面から $3 \mathrm{~mm}$ 離れた 位 㯰に

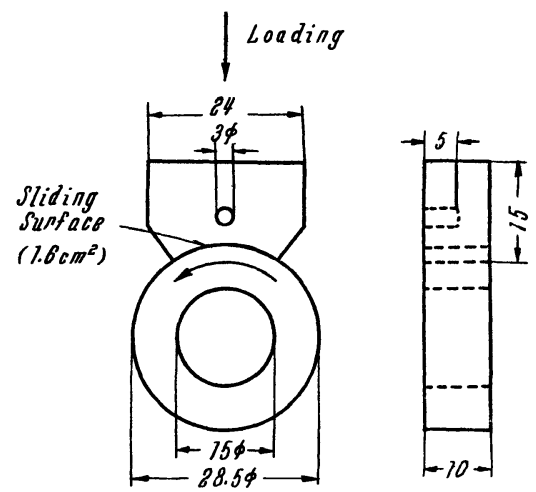

あけた直径 $3 \mathrm{~mm}$ の孔 に熱電対を 捙入して测 定し、また 摩擦係数 $\mu$ は次式より 算出した. $\mu=M / r \cdot p$ ただし $M:$ 摩擦乇 メ

Fig. 1 Wear test specimens.

ソト, $r:$ 回

\section{3. 機械試験ならびに耐食試験}

抗張試験片はJIS 4 号試験片に準じた試験片 $(\phi=7 \mathrm{~mm}$, G.L. $=25 \mathrm{~mm})$, シャルピー衝撃試験片は JIS 3 号試験片 $\left(10 \times 10 \times 55 \mathrm{~mm}, 2 \mathrm{~mm} \mathrm{U}\right.$ ノッチ)を用い，これらを $850^{\circ}$ に括いて窒化して陚験に供した.

耐食試験には $1.5 \times 10 \times 25 \mathrm{~mm}$ の試片をエメリ一紙 No.

Table 2 Results of wear test under unlubricated condition.

(slided distance : $324 \mathrm{~m}$ )

\begin{tabular}{|c|c|c|c|c|c|}
\hline \multicolumn{2}{|c|}{ Combination } & \multicolumn{2}{|c|}{$\begin{array}{l}\text { Wear loss } \\
\left(\mathrm{mg} / \mathrm{cm}^{2}\right)\end{array}$} & \multirow{2}{*}{$\begin{array}{c}\text { Coefficient } \\
\text { of } \\
\text { friction }\end{array}$} & \multirow{2}{*}{ Remarks } \\
\hline fixed piece & rotary piece & $\begin{array}{l}\text { fixed } \\
\text { piece }\end{array}$ & $\begin{array}{l}\text { rotary } \\
\text { piece }\end{array}$ & & \\
\hline $\begin{array}{l}\mathrm{Ti} \\
" 1 \\
" 1 \\
" 1 \\
" 1\end{array}$ & $\mid \begin{array}{l}\mathrm{Ti} \\
18-8 \text { Stainless steel } \\
\text { Bronze } \\
\text { Hastelloy C } \\
\text { Cast iron } \\
\text { Carbon steel }\end{array}$ & $\begin{array}{r}18.7 \\
22.7 \\
0.1 \\
7.5 \\
7.8 \\
2.2\end{array}$ & $\begin{array}{r}5.3 \\
2.7 \\
92.6 \\
8.2 \\
10.4 \\
6.3\end{array}$ & $\begin{array}{l}0.58 \\
0.51 \\
0.73 \\
0.73 \\
0.58 \\
0.58\end{array}$ & $\begin{array}{l}\text { heavy roughening of seizured surface } \\
\text { many scratch traces } \\
\text { great wear loss of bronze } \\
\text { many scratch traces } \\
\text { relatively smooth } \\
\text { scratch traces }\end{array}$ \\
\hline $\begin{array}{c}\text { Nitrided Ti } \\
" 1 \\
" \\
" \\
" \\
" \\
" \\
"\end{array}$ & $\begin{array}{l}\text { Ti } \\
\text { Nitrided Ti } \\
\text { 18-8 Stainless steel } \\
\text { Bronze } \\
\text { Hastelloy C } \\
\text { Cast iron } \\
\text { Carbon steel } \\
\text { Hard Cr plating }\end{array}$ & $\begin{array}{r}1.6 \\
2.3 \\
10.4 \\
1.2 \\
5.0 \\
0.7 \\
0.1 \\
3.0\end{array}$ & $\begin{array}{l}3.9 \\
0.1 \\
5.1 \\
0.5 \\
3.4 \\
0.6 \\
0.5 \\
0.7\end{array}$ & $\begin{array}{l}0.51 \\
0.36 \\
0.44 \\
0.44 \\
0.58 \\
0.51 \\
0.80 \\
0.58\end{array}$ & $\begin{array}{l}\text { scratched surface } \\
\text { smooth } \\
\text { tendency of surface roughening } \\
\text { relatively smooth } \\
\text { scratch traces } \\
\text { smooth } \\
\text { tendency of surface roughening } \\
\text { smooth }\end{array}$ \\
\hline
\end{tabular}

試験を行い,摩耗量,温度上昇扣よび摩擦係数の測定を行つ た. 試験片の大きさおよび摩擦状況はFig.1に示すようで ある、試験片は予め全面研摩仕上げした後前報(3)で述べた 方法により窒素ガス中で $850^{\circ} \times 16 \mathrm{hr}$ の窒化処理を行い試 験に供した，摩耗試験条件としては実用性ならびに試験結 果の比較の容易さなどを考慮して乾燥状態では荷重 $3 \mathrm{~kg}$ y $\mathrm{cm}^{2}$, 周速 $0.6 \mathrm{~m} / \mathrm{sec}$, 給油状態では荷重 $10 \mathrm{~kg} / \mathrm{cm}^{2}$, 周 速 $0.3 \mathrm{~m} / \mathrm{sec}$ とした。潤滑油はモビール油 \#30を使用し

（1）吉田，磯野：機峨試験所々報，10(1956)，78.

(2) K.Bungardt u.K.Rüdinger: Z. Metallk., 47 (1956) ,577.

（3）高村：本誌, 24 (1960) No.9.
05 まで研摩した後 $850^{\circ} \times 16 \mathrm{hr}$ の窒化を行つたものを試 験片とした.

\section{III. 実 験 結 果}

\section{1. 耐摩耗 性}

Fig.2 は乾燥状態に拈ける試験結果の一例であるが，窒 化により Ti の耐摩耗性は著しく改善されている. 摩耗距 離を $324 \mathrm{~m}$ 一定とし窒化処理 $\mathrm{Ti}$ 打よび $\mathrm{Ti}$ と各種材料と を組合せた場合の乾燥状態に打ける試験結果をまとめると Table 2 のようになる.すなわち Ti と他の材料との組合 せに拈いてはいずれも摩耗量が大きくかつ摩摖面の荒れが 激しく, この傾向は特に Ti-Ti, Ti-ステンレス鋼扣よび Ti-青銅の組合せにおいて著しい，一方窒化処理 $\mathrm{Ti}$ との 
組合せに扣いては括〉むね摩耗量は小さく，摩摖面の外観 む良好であり，窒化の効果が明瞭に顕われている。しかし

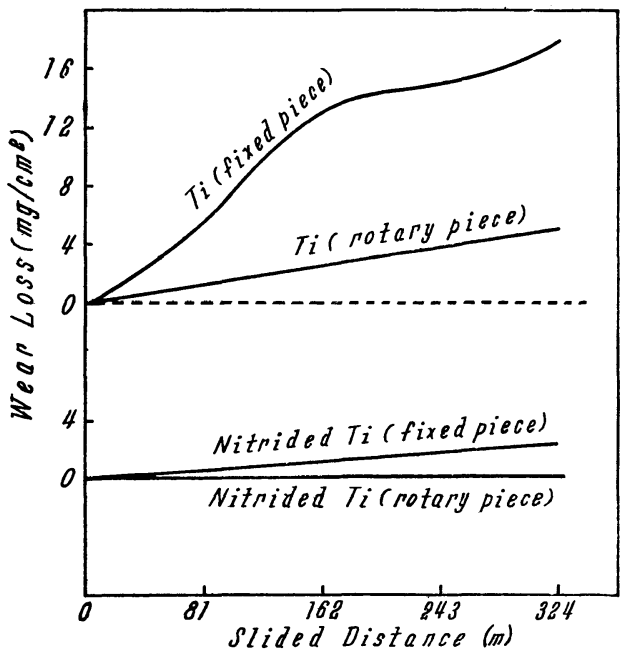

Fig.2 Wear curves of $\mathrm{Ti}$ and nitrided $\mathrm{Ti}$ under unlubricated condition.
イトおよびベークライトとの組合せならびに窒化処理 $\mathrm{Ti}$ 同志の組合せについて長距離摩耗試験を行つた結果を

Table 4 に示す. Ti-青銅の組合せに拈いては摩耗距離の

Table 4 Results of wear test under lubricated condition for long slided distance.

\begin{tabular}{|c|c|c|c|c|}
\hline \multicolumn{2}{|c|}{ Combination } & \multirow{2}{*}{$\begin{array}{l}\text { Slided } \\
\text { dis- } \\
\text { tance } \\
(\mathrm{m})\end{array}$} & \multicolumn{2}{|c|}{$\begin{array}{l}\text { Wear loss } \\
\left(\mathrm{mg} / \mathrm{cm}^{2}\right)\end{array}$} \\
\hline fixed piece & rotary piece & & $\begin{array}{l}\text { fixed } \\
\text { piece }\end{array}$ & $\begin{array}{r}\text { rotary } \\
\text { piece }\end{array}$ \\
\hline $\begin{array}{c}\text { Nitrided } \mathrm{Ti} \\
\text { ", } \\
\text { " } \\
\text { " } \\
\text { " }\end{array}$ & $\begin{array}{l}\text { Nitrided Ti } \\
\text { " } \\
\text { Bronze" } \\
\text { Cast iron } \\
\text { Carbon steel } \\
\text { Low alloy } \\
\text { steel } \\
\text { Carbabte } \\
\text { " } \\
\text { Bakelite } \\
\text { Bronze }\end{array}$ & $\begin{array}{r}8,127 \\
90,000 \\
8,127 \\
90,000 \\
8,127 \\
8,127 \\
8,127 \\
8,127 \\
90,000 \\
8,127 \\
8,127\end{array}$ & $\begin{array}{l}1.2 \\
1.6 \\
0.1 \\
0.2 \\
0.7 \\
0.1 \\
1.0 \\
0.6 \\
0.8 \\
0.7 \\
0.5\end{array}$ & $\begin{array}{r}0.2 \\
0.3 \\
0.8 \\
1.0 \\
0.4 \\
0.9 \\
2.0 \\
0.0 \\
0.0 \\
0.0 \\
10.0\end{array}$ \\
\hline
\end{tabular}

延長とともに摩耗量が増加するが, 窒化処理 $\mathrm{Ti}$ と他の材 料との組合せに拈いては長距離摩耗においても窒化層の䟝

Table 3 Results of wear test under lubricated condition.

(slided distance : $108 \mathrm{~m}$ )

\begin{tabular}{|c|c|c|c|c|c|}
\hline \multicolumn{2}{|c|}{ Combination } & \multicolumn{2}{|c|}{$\begin{array}{l}\text { Wear loss } \\
\left(\mathrm{mg} / \mathrm{cm}^{2}\right)\end{array}$} & \multirow{2}{*}{$\begin{array}{c}\text { Coefficient } \\
\text { of } \\
\text { friction }\end{array}$} & \multirow{2}{*}{ Remarks } \\
\hline fixed piece & rotary piece & $\begin{array}{l}\text { fixed } \\
\text { piece }\end{array}$ & $\begin{array}{l}\text { rotary } \\
\text { piece }\end{array}$ & & \\
\hline $\begin{array}{l}\mathrm{Ti} \\
" 1 \\
" 1 \\
" 1 \\
" 1\end{array}$ & $\begin{array}{l}\mathrm{Ti} \\
18-8 \text { stainless steel } \\
\text { Bronze } \\
\text { Hastelloy C } \\
\text { Cast iron } \\
\text { Carbon steel }\end{array}$ & $\begin{array}{r}85.0 \\
15.0 \\
0.3 \\
8.4 \\
3.6 \\
2.0\end{array}$ & $\begin{array}{r}10.0 \\
4.0 \\
0.6 \\
10.0 \\
2.0 \\
13.0\end{array}$ & $\begin{array}{l}0.52 \\
0.45 \\
0.11 \\
0.30 \\
0.10 \\
0.45\end{array}$ & $\begin{array}{l}\text { scratch traces } \\
\text { tendency of seizing } \\
\text { smooth } \\
\text { scratched surface } \\
\text { relatively smooth } \\
\text { tendency of seizing }\end{array}$ \\
\hline $\begin{array}{c}\text { Nitrided } \mathrm{Ti} \\
\text { " } \\
" \\
" \\
" \\
" \\
" \\
" \\
" \\
"\end{array}$ & $\begin{array}{l}\text { Ti } \\
\text { Nitrided Ti } \\
\text { 18-8 Stainles steel } \\
\text { Bronze } \\
\text { Hastelloy C } \\
\text { Cast iron } \\
\text { Carbon steel } \\
\text { Low alloy steel } \\
\text { Carbaite* } \\
\text { Bakelite }\end{array}$ & $\begin{array}{r}3.7 \\
0.9 \\
25.0 \\
0.0 \\
22.0 \\
0.4 \\
0.0 \\
0.6 \\
0.6 \\
0.5\end{array}$ & $\begin{array}{r}11.9 \\
0.2 \\
7.4 \\
0.5 \\
8.7 \\
0.2 \\
0.7 \\
0.7 \\
0.0 \\
0.0\end{array}$ & $\begin{array}{l}0.49 \\
0.10 \\
0.40 \\
0.13 \\
0.40 \\
0.11 \\
0.11 \\
0.13 \\
0.13 \\
0.13\end{array}$ & $\begin{array}{l}\text { Smooth } \\
\text { Smooth } \\
\text { Seizured surface } \\
\text { Smooth } \\
\text { Seizured surface } \\
\text { Smooth } \\
\text { Smooth } \\
\text { Smooth } \\
\text { Smooth } \\
\text { Smooth }\end{array}$ \\
\hline
\end{tabular}

* made by National Carbon Co., U.S.A

窒化処理 $\mathrm{Ti}$ - ステンレス鋼および窒化処理 $\mathrm{Ti}$-ハステロ イCの組合せに扣いてはなおかなりの摩損を生じ耐摩耗 性は充分でない。また窒化処理 $\mathrm{Ti}$ - Ti の組合せに拈いて はTi 側に引蛍きを生ずる。

Table 3は摩耗距離 $108 \mathrm{~m}$ における給油試験の結果で あるが，乾燥試験の場合とほぼ同様な傾向を示し，いずれ の組合せに拈いても窒化に上る耐摩耗性改善効果は顕著で ある。しかし乾燥陚験の場合と同じく窒化処理 Ti-ステン レス鋼および窒化処理 $\mathrm{Ti}$-ハステロイCの組合せにおいて はなお耐摩耗性は充分でない。Ti-青銅の組合せは給油状 態では良好な耐摩耗性を示しているが，Tiに対する閵滑 剤の効果としてはむしろ特異な例である*.

以上述べた比較的短時間の試験に打いて良好な結果を示 した空化処理 $\mathrm{Ti}$ と青銅, 鋳鉄, 炭素鋼, 低合金鋼，カーバ
離を生ずることなく依然として良好な耐摩耗性を示してい る。な拈用いた窒化処理 $\mathrm{Ti}$ は $850^{\circ} \times 16 \mathrm{hr}$ の窒化を行い 硬化層の厚さは約 $50 \mu$ であるが, 窒化時間を $72 \mathrm{hr}$, 硬化 層の厚さを約 $80 \mu$ としたものについても同様な結果が得 られた．また固定片の摩擦による温度上䄯はいずれの組合 せに拈いても 10 〜0の範囲内にあつたが，摩耗量が大な る場合洼ど温度上年も大であり，摩摖係数とほぼ同様な傾 向を示した。

\section{2. 機 械的 性 翼}

* Ti は通常の潤滑荗に対するなじみが悪いため㵎滑 効果がないとされて拈り (4), 著者らの実験においても数 種類の液状ならびにグリース状の潤滑剤は Ti-青銅以外 の組合せではその効果は殆んど認められなかつた。

(4) E.Rabinowicz: Metal Progr., 65(1954),107. 


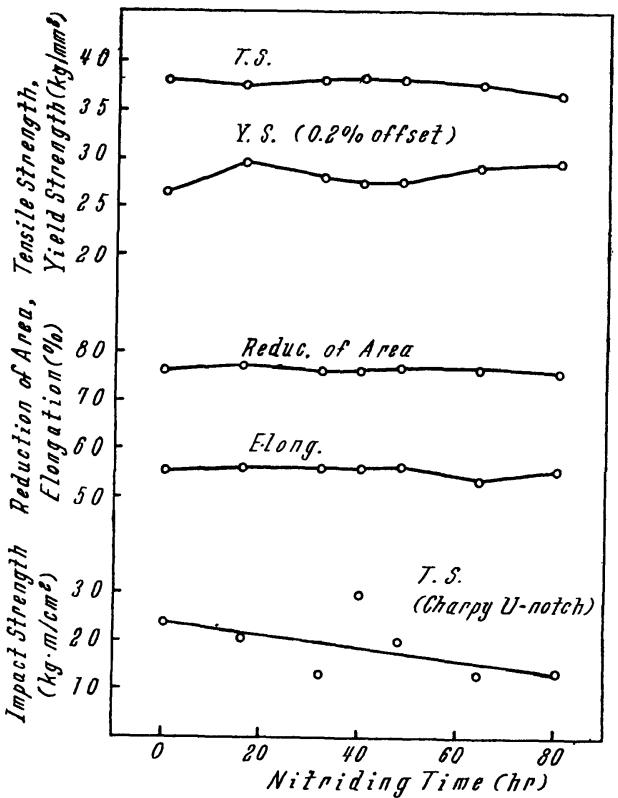

Fig.3 Effect of nitriding on the mechanical properties of $\mathrm{Ti}$.
ヤルピー衝撃値は窒化時間とともに低下するが, $80 \mathrm{hr}$ 窒

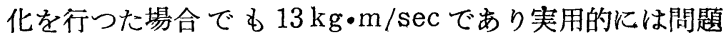

Table 6 Corrosion resistance of nitrided $\mathrm{Ti}$, the surface film of which is stripped off.

\begin{tabular}{c|r|r|r}
\hline & $\begin{array}{c}\text { Duration } \\
\text { of test } \\
\text { (hr) }\end{array}$ & $\begin{array}{r}\text { Corrosion rate } \\
\text { (mil/y) }\end{array}$ \\
\cline { 3 - 5 } & $\begin{array}{c}\text { Nitrided } \\
\text { Ti* }\end{array}$ & $\mathrm{Ti}$ \\
\hline $\mathrm{HCl} 1 \%$ boiling & 8 & 27 & 25 \\
" $3 \%$ boiling & 8 & 95 & 146 \\
" 30\% 30 & 240 & 146 & 225 \\
\hline $\mathrm{H}_{2} \mathrm{SO}_{4} 1 \%$ boiling & 8 & 122 & 104 \\
" 3\% boiling & 8 & 593 & 603 \\
" 75\% 30 & 240 & 188 & 325 \\
\hline $\mathrm{HNO}_{3} 65 \%$ boiling & 8 & 34 & 32 \\
\hline
\end{tabular}

* The surface film was stripped off by dipping in boiling $65 \% \mathrm{HNO}_{3}$ for $5 \mathrm{hrs}$.

にならないと考えられる. Bungardt-Rüdinger(2) の報告 によれば $850^{\circ} \times 48 \mathrm{hr}$ の窒化によつて衝撃值のみならず, 伸ひ打よび絞りも相当低下しているが，これは彼等の実験 に打いては窒化雲囲気中に酸素が混入していた疑いがあり
Table 5 Corrosion resistance of $\mathrm{Ti}$ nitrided at $850^{\circ}$ for $16 \mathrm{hr}$.

\begin{tabular}{|c|c|c|c|}
\hline \multirow{2}{*}{ Environment } & \multirow{2}{*}{$\begin{array}{l}\text { Duration of } \\
\text { test (hr) }\end{array}$} & \multicolumn{2}{|c|}{$\begin{array}{c}\text { Corrosion rate } \\
(\mathrm{mil} / \mathrm{y})\end{array}$} \\
\hline & & Nitrided $\mathrm{Ti} \mid$ & $\mathrm{Ti}$ \\
\hline $\begin{array}{ccc}\mathrm{HCl} & 1 \% & \text { boiling } \\
\text { " } & 3 \% & \text { boiling } \\
\text { " } & 5 \% & \text { boiling } \\
" & 10 \% & \text { boiling } \\
" & 10 \% & 30^{\circ} \\
" & 20 \% & 30^{\circ} \\
" & 30 \% & 30^{\circ} \\
& 35 \% & 30^{\circ}\end{array}$ & $\begin{array}{r}8 \\
8 \\
8 \\
8 \\
240 \\
240 \\
240 \\
240\end{array}$ & $\begin{array}{c}0 \\
0 \\
3.0 \\
365 \\
0 \\
0 \\
0.4 \\
580\end{array}$ & $\begin{array}{c}25 \\
146 \\
382 \\
2,200 \\
7.0 \\
53 \\
225\end{array}$ \\
\hline 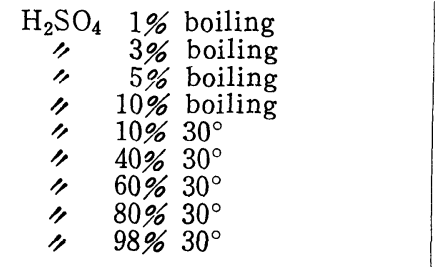 & $\begin{array}{r}8 \\
8 \\
8 \\
8 \\
240 \\
240 \\
240 \\
240 \\
240\end{array}$ & $\begin{array}{r}0 \\
0 \\
29 \\
410 \\
0 \\
0 \\
0 \\
0 \\
0\end{array}$ & $\begin{array}{r}11 \\
45 \\
11 \\
1,300\end{array}$ \\
\hline $\begin{array}{ccl}\mathrm{H}_{3} \mathrm{PO}_{4} & 10 \% & \text { boiling } \\
\text { " } & 50 \% & 30^{\circ} \\
\mathrm{HF}^{\circ} & 1 \% & 30^{\circ} \\
\mathrm{HNO}_{3} & 65 \% & 30^{\circ} \\
\text { " } & 65 \% & \text { boiling }\end{array}$ & $\begin{array}{r}8 \\
240 \\
240 \\
240 \\
8\end{array}$ & $\begin{array}{c}20 \\
0 \\
\text { dissolved } \\
2.2 \\
180\end{array}$ & $\begin{array}{c}410 \\
3.8 \\
\text { dissolved } \\
0 \\
32\end{array}$ \\
\hline 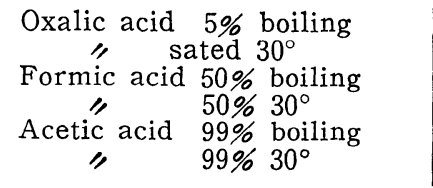 & $\begin{array}{r}8 \\
240 \\
8 \\
240 \\
8 \\
240\end{array}$ & $\begin{array}{l}9.0 \\
0 \\
9.6 \\
0 \\
0 \\
0\end{array}$ & $\begin{array}{r}1,100 \\
14\end{array}$ \\
\hline $\begin{array}{l}\text { Ferric chloride } 10 \% \text { boiling } \\
\text { Aluminum chloride } 25 \% \text { boiling } \\
\text { Wet } \mathrm{Cl}_{2}, 100^{\circ}\end{array}$ & $\begin{array}{r}8 \\
8 \\
240\end{array}$ & $\begin{array}{l}0 \\
0 \\
0\end{array}$ & $\begin{array}{l}0 \\
0 \\
0\end{array}$ \\
\hline
\end{tabular}

\section{3. 耐食性}

Table 5 は $850^{\circ} \times 16 \mathrm{hr}$ の窒化を行つた 試片について各種の䗪食環境に拈いて耐食 試験を行つた結果である．硝酸を除いては いずれの環境においても窒化により耐食性 は向上しているが，これはステンレス鋼の 窒化の場合と著しく異なるところである. 硝酸に対して耐食性が德くなるのは最表面 の化合物缯が硝酸に溶解するためである。 この化合物層は厚さ約 $3 \mu$, 外観は黄金色 であり, 常温の濃硝酸に $20 \mathrm{~min}$ 浸漬する と黄金色は消えて鉛色となるが，溶解は最 表面部のみに限られ化合物層は殆んど残つ ている.これをさらに $5 \mathrm{hr}$ 沸滕濃硝酸中 に浸漬すると完全に溶解する.このように 化合物層を溶解し去つたものについて塩 酸, 硫酸および硝酸中に扣いて耐食試験を 行つた結果はTable 6のようであり，化合 物層を溶解し去つた後は未処理の Ti とほ ぼ同じ閦食举動を示している.

硝酸を除いた他の環境においてて耐食性が 向上するのは窒化により表面た TiNを市

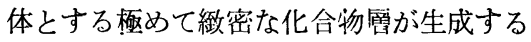
ためと考えられるが，上記の陚験は比較的 短時間であるためこのよ5な被膜の防食効
Fig.3 は $850^{\circ}$ に括ける窒化時間と機械的性質との関係 を示すものであるが, $80 \mathrm{hr}$ の窒化によつても抗張力, 耐 力，伸びおよび絞りは未処理の Ti と殆んど変らない、シ
* Bungardt-Rüdinger $の$ 得た硬化層つ厚さは $850^{\circ}$ $\times 48 \mathrm{hr}$ 窒化の場合 $240 \mu$ 以上であり, これは窒素のみ による拡散層とは考えられず，さしろかなり多量の酸 素が混入しているものと考えなければならない， Ti 中に打ける酸素の桩散については別に報告する。 
果の信頼性てついてはな唁討を要すると思われる. しか しいずれにしても窒化により $\mathrm{Ti}$ の耐食性が劣下すること はなく，また硝酸などの酸化性環境において使用した場合 でも耐摩耗性に寄与するのは内部の硬化層であるため表面 の化合物層が溶解しても差支えないものと考えられる.

\section{IV. 総 括}

窒素ガスにより $850^{\circ}$ に拈いて $16 \sim 80 \mathrm{hr}$ 窒化した $\mathrm{Ti}$ の 耐摩耗性, 機械的性質ならびに酎食性について Ti と比較 試験を行い，次のような結果が得られた。

(1) Ti は Ti 同志あるいは異種金属と摩擦した場合極め て熔着し易すく潤滑剤とのなじみる悪いが, 窒化によりそ の耐摩耗性は著しく改善される.すなわち窒化処理 Ti は無 潤滑状態では鋳鉄, 硬質クロム鍍金および窒化処理 $\mathrm{Ti}$ と の組合せに扣いて，また潤滑状態では青銅,鋳鉄,炭素鋼,
低合金鉵，カーバイト，ベークライトおよび窒化処理 $\mathrm{Ti}$ との組合せに拈いては極めて良好な摩擦性質を示す．乙か しステンレス鋼およびハステロイC との組合せたおける耐 摩耗性は充分でない.

（2）窒化により $\mathrm{Ti}$ の抗 張 性質は殆んど影響を受けな い.衝撃値は若干低下するが実用上差支えない程度である.

（3）還元性の環境に扣ける $\mathrm{Ti}$ の耐食性は窒化により改 善される.これは窒化により表面に生成する緻密な化合物 層による防食効果のためと考えられる．この化合物瘄は硝 酸などの強酸化性環境においては比較的容易に溶解する が,一旦溶解した後に拈いては窒化処理 $\mathrm{Ti}$ は末処理 $\mathrm{Ti}$ と ほぼ同様な電食挙動を示すに至る，従つて全体として Ti の耐食性は窒化により劣下することはない.

終りに本研究の㴚行に当つて種々御指導賜つた当社研究 部長高尾善一郎氏に深く感謝する次第である. 